\title{
Subclavian artery stenosis as a cause of acute coronary syndrome in a patient after coronary artery bypass grafting
}

Arkadiusz Derkacz ${ }^{1}$, Jacek Bezubka², Roman Szełemej

1Department of Internal Medicine, Occupational Disease and Hypertension, Wroclaw Medical University, Poland

2Department of Cardiology, Sokolowski Hospital, Walbrzych, Poland

Submitted: 14 June 2010

Accepted: 25 October 2010

Arch Med Sci 2011; 7, 5: 905-908

DOI: 10.5114/aoms.2011.25570

Copyright ๑ 2011 Termedia \& Banach

\section{Abstract}

We described a case of a 74-year-old man who suffered from acute coronary syndrome 7 years after coronary artery bypass grafting. The patient underwent angioplasty of the obtuse marginal branch of the left coronary artery from venous graft access, which did not result in relief of ailments. Only angioplasty of the narrowed subclavian artery caused an improvement in the patient's condition. The clinical significance of narrowing within the subclavian artery in patients after the procedure of implanting the left subclavian artery into the coronary artery system was discussed.

Key words: subclavian artery angioplasty, peripheral stenting, coronary angioplasty, left internal mammary artery.

\section{Introduction}

Stenosis within the subclavian artery occurs in $0.5-7.1 \%$ of patients in the course of advanced atherosclerosis [1, 2]. In most cases it is asymptomatic; however, it may occur in the form of subclavian steal syndrome. In patients after coronary artery bypass graft (CABG) surgery using the left internal mammary artery (LIMA), the proximal narrowing of the left subclavian artery may cause an increase in stenocardial pain, and in extreme cases it may result in the occurrence of acute coronary syndrome. This is exactly the case we would like to describe.

\section{Case report}

A 74-year-old male with generalized atherosclerosis being the cause of ischaemic heart disease, abdominal aortic and right common iliac artery aneurysm, subacute ischaemia of the left leg with dry necrosis of the $5^{\text {th }}$ toe of the left foot, and also with renal failure, arterial hypertension and permanent atrial fibrillation, was hospitalised due to acute coronary syndrome with additional troponin values. So far, the coronary disease observed in this case has revealed itself in the form of two myocardial infarctions, which took place 25 and 23 years ago, and which compromised left ventricular ejection fraction to about $30 \%$, as well as the necessity to perform CABG 7 years ago. The procedure was performed by implantation of two venous grafts: to the right coronary artery (RCA) and the obtuse

\section{Corresponding author:}

Assoc. Prof. Arkadiusz Derkacz

Department of Internal Medicine,

Occupational Disease and Hypertension

Wroclaw Medical University

213 Borowska

50-556 Wroclaw, Poland

Phone/fax: +48717364000

E-mail:

aderkacz@chirs.am.wroc.pl 
marginal branch of the left coronary artery (OM), together with LIMA to the left anterior descending artery (LAD). When admitted, the patient suffered from recurring stenocardial pain. The ECG record did not reveal any diagnostic features due to permanent atrial fibrillation and left bundle branch block.

Because of the whole clinical image, including troponin values exceeding the normal range 2.5 times, the decision was made to perform coronary angiography. Due to significant atherosclerotic and ischaemic lesions within lower limbs, abdominal aortic aneurysm and very weakly palpable pulse within the scope of the left radial artery (the difference in systolic pressure in both limbs was about $20 \mathrm{mmHg}$, to the benefit of the right one) the procedure was performed from the puncture of the right radial artery. Advanced lesions within coronary arteries were observed, with amputation of the RCA and circumflex artery, next to numerous lesions within the remaining coronary vessels.

Angiography of venous grafts to the RCA and OM revealed their proper functioning; nevertheless, native circumflex arteries, the $\mathrm{OM}$ in particular, revealed advanced atherosclerotic changes. In the

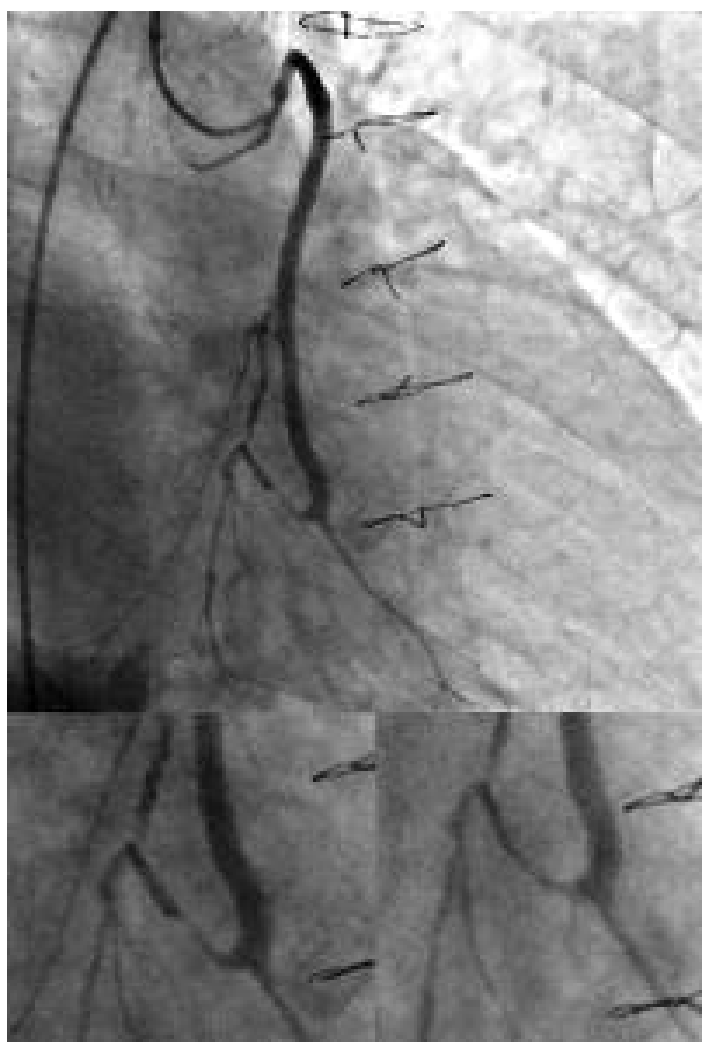

Figure 1. Circumflex coronary artery with narrow stenosis proximal to the place of vein graft implantation (upper part - general view; lower part, left - place of stenosis). Coronary balloon angioplasty (without stent implantation because of small artery diameter) executed by retrograde technique through graft was effective (lower, right part) light of the angiographic image, mentioned above, the patient underwent angioplasty with stent implantation within the scope of OM, with retrograde technique, through a venous bridge (Figure 1). Despite the successful course of the procedure, it was impossible to obtain relief of recurring stenocardial ailments or troponin level normalization. In relation to the above, despite relative contraindications, the decision was made to perform LIMA angiography from the right femoral artery puncture, as it is inaccessible to be evaluated from the right radial artery puncture. The examination revealed narrow stenosis of the left subclavian artery within its initial segment. Angioplasty was performed; a stent was implanted which led to widening of the vessel (Figure 2). The

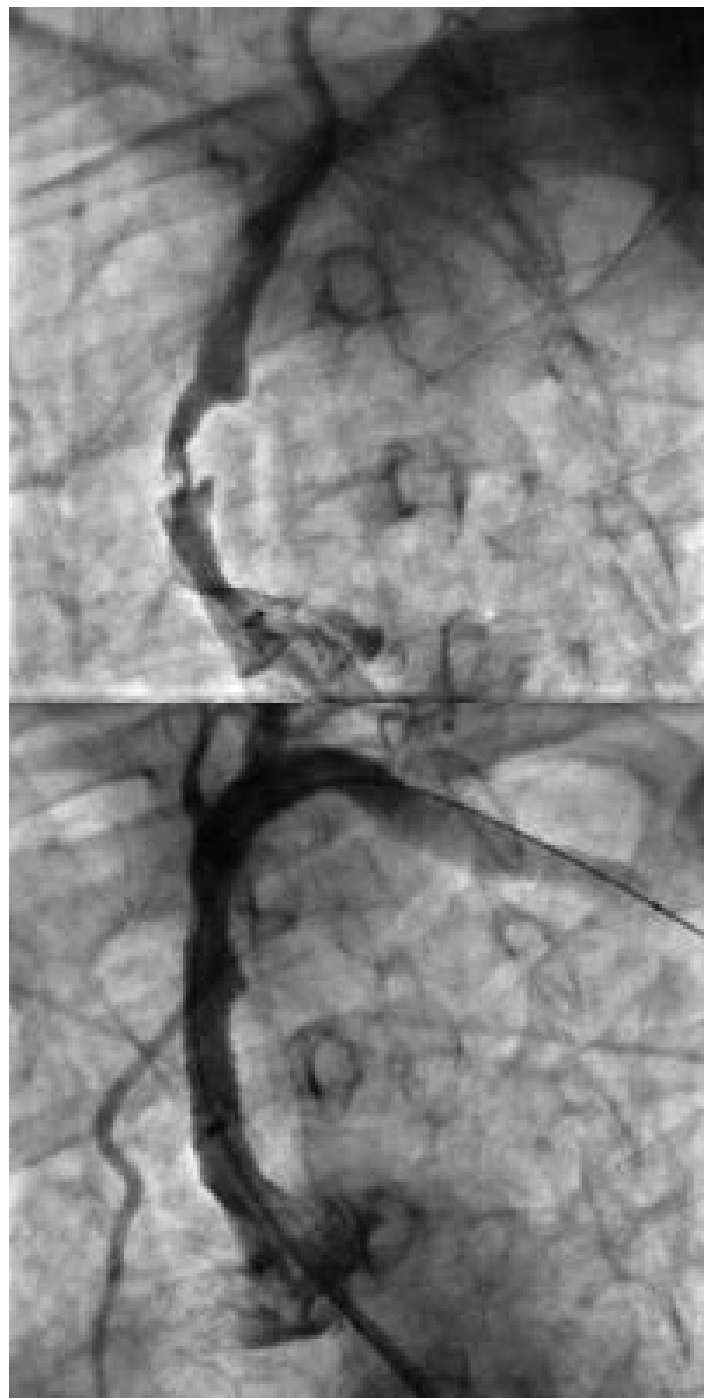

Figure 2. Left subclavian artery with narrow stenosis before the occurrence of internal mammary artery implanted in the left anterior descending coronary artery (upper part). Angioplasty with stent implantation in the subclavian artery also caused blood flow improvement in the internal mammary artery (lower part) 
procedure resulted in distinct angiographic improvement in the flow within the LIMA, relief of stenocardial ailments and gradual normalization of troponin level.

\section{Discussion}

Despite the observed incidental long lifespan of venous grafts [3], the LIMA is the best bridge used in CABG due to its long lifespan and lack of atherosclerotic lesions. Among other things this is related to increased nitric oxide production by the LIMA, in comparison with other grafts. It is a spasm protecting activity and one limiting the development of arteriosclerosis, not only within the thoracic artery, but also in the peripheral segment of the coronary artery into which the graft is implemented. Unfortunately, in the case of significant stenosis or even proximal closure of the subclavian artery from the place of LIMA exit, which is a typical location of the lesion, it may lead to damage of the flow and even its inversion within the LIMA [4]. It leads to intensified symptoms of subclavian artery syndrome or acute coronary syndrome [5]. Diagnostics related to possible stenosis within the subclavian artery are based on arterial pressure measures, Doppler test and classical angiography or performed by means of computed tomography or magnetic resonance imaging. The difference in systolic pressure within the scope of upper limbs equalling at least $15 \mathrm{mmHg}$ is treated as a factor indicating a significant probability of noteworthy haemodynamic stenosis within the subclavian artery [1]. In the case of classical angiographic examination it is impossible to perform the procedure from the puncture of the radial artery opposite to the diagnosed artery. The evaluation of the subclavian artery should be performed before the CABG procedure and after the procedure performed with the left and/or right thoracic artery in case of intensification of stenocardial ailments or occurrence of acute coronary syndrome. Angioplasty of the subclavian artery combined with stent implantation is characterized by high efficiency and good long-term results [6-8].

There are no unambiguously accepted criteria concerning the type and dimension of lesion within the subclavian artery that requires angioplasty. It seems that coexistence of ischaemia in the upper limb or in the brain, and in the case of implementing the LIMA to the coronary artery also the symptoms of ischaemic heart disease, constitute the indication for the procedure. Such clinical symptoms are usually related to stenosis in the subclavian artery, equalling at least $50 \%$. It has been stated that stenosis not exceeding $50 \%$ is related to the difference in blood pressure in the brachial arteries, which does not exceed $20 \%$. Angioplasty is considered successful when stenosis is decreased to less than $30 \%$, which in the majority of cases relates the balance of pressure on both upper limbs. Further pressure monitoring is an efficient method of clinical observation related to the occurrence of restenosis [9].

The described case was one of the most difficult ones because of advanced atherosclerotic lesions limiting the vascular access, renal failure forcing us to limit the amount of contrast agent and the necessity of immediate action related to increasing troponin values. The patient underwent a previous coronary angioplasty procedure within the scope of the narrowed circumflex artery, performed by means of a technically quite difficult retrograde method through the venous bridge [10], which did not lead to relief of the acute coronary syndrome, but probably led to improvement in cardiac muscle perfusion.

In conclusion, patients before CABG performed on schedule and after the procedure with the internal thoracic artery in the case of increase in coronary ailments should be diagnosed from the view of narrowing within the subclavian artery.

Angioplasty of the narrowed subclavian artery is a relatively safe procedure and it can result in an improvement of clinical condition in patients after CABG with the thoracic artery with intensified symptoms of the coronary artery.

\section{References}

1. Beribeau Y, Westbrook BM, Charlesworth DC, Hearne MJ, Bradley WA, Maloney CT. Brachial gradient in cardiac surgical patients. Circulation 2002; 106 (Suppl 1): I11-3.

2. Shadman R, Criqui MH, Bundens WP, et al. Subclavian artery stenosis: prevalence, risk factors, and association with cardiovascular diseases. J Am Coll Cardiol 2004; 44: 618-23.

3. Ugurlucan M, Hansel T, Umman S, Erzengin F, Calay MR, Onursal E. Saphenus vein graft marker and coronary artery bypass graft stenosis in a patient 19 years after coronary artery bypass surgery. Arch Med Sci 2007; 3: 399-401.

4. Derkacz A, Nowicki P, Śliwiński T, Pelczar M. Subclaviancoronary steal syndrome following CABG: a case report. Kardiol Pol 2003; 59: 514-6.

5. Latacz P, Rostoff P, Rudnik A, Kondys M, Buszman P. Percutaneous revascularisation of subacute occlusion of the left subclavian artery manifesting as acute coronary syndrome in a patient after coronary artery bypass grafting. Kardiol Pol 2010; 68: 226-9.

6. Angle JF, Matsumoto AH, McGraw JK, et al. Percutaneous angioplasty and stenting of left subclavian artery stenosis in patients with left internal mammary-coronary bypass grafts: clinical experience and long-term follow-up. Vasc Endovascular Surg 2003; 37: 89-97.

7. Elian D. Gerniak A, Guetta V, et al. Subclavian coronary steal syndrome: an obligatory common fate between subclavian artery, internal mammary graft and coronary circulation. Cardiology 2002; 97: 175-9.

8. Przewlocki T, Kablak-Ziembicka A, Pieniazek P, et al. Determinants of immediate and long-term results of subclavian and innominate artery angioplasty. Catheter Cardiovasc Interv 2006; 67: 519-26. 
9. Ostrowski T, Macioch W, Małek AK, et al. Long-term results after percutaneous transluminal angioplasty of the subclavian artery. Acta Angiol 2001; 7: 99-104.

10. Gulbaran M, Gemici G. Retrograde balloon dilatation of right coronary artery lesions through a venous graft. Int J Cardiol 200; 136: e58-9. 